\title{
Competitive Intelligence Among SMEs: Assessing the Role of Entrepreneurial Attitude Orientation on Innovation Performance.
}

Completed Research Paper

\author{
$1^{\text {st }}$ Ainul Mohsein Abdul-Mohsin \\ Univerisiti Sains Malaysia \\ amam11_man095@student.usm.my \\ $3^{\text {rd }}$ Noor Haslina Ahmad \\ Universiti Sains Malaysia \\ hazlina@usm.my
}

\author{
$2^{\text {nd }}$ Hasliza Abdul-Halim \\ Universiti Sains Malaysia \\ haslizahalim@usm.my
}

\begin{abstract}
Competitive intelligence is key in today's unstable global environment because it leads to creation of ideas and innovation. Yet, research on competitive intelligence as the foundation of strategic management is very much lacking. Furthermore, research on competitive intelligence practice among the SMEs is also scanty. Thus, the intention of this study is to review the literature on entrepreneurial attitude orientation, competitive intelligence and innovative performance and to investigate the relationships of these three variables within the Malaysian SME context with empirical evidence.
\end{abstract}

Keywords: Competitive intelligence, Entrepreneurial attitude orientation, Innovative performance, SME.

\section{Introduction}

In recent years, the Malaysian SME sector has soared in accordance with the global business development. The government continues to provide various support in the form of development programmes and funding to escalate the SMEs productivity (PEMANDU, 2010). Nevertheless, the SMEs contributes to only $32.5 \%$ of the country's GDP (Star Business, 2013). The 2014-2015 Competitive Index chart ranked Malaysia at twentieth in terms of competitiveness and at thirty-third on the 2014 Global Innovation Index for innovativeness. From these rankings it is obvious that the Malaysian organisations lack innovativeness. Therefore, for them to sustain, they need to enhance on their innovativeness, creativity and entrepreneurship.

In the western hemisphere and East Asia, competitive intelligence (CI) is being heavily utilised by large and smaller organisations (Adidam, Banerjee, \& Shukla, 2012; Priporas, Gastoris, \& Zacharis, 2005) as a source for competitive advantage and innovativeness (Smith \& Kossou, 2008; Wright, 2011). A review of the literature also shows a positive relationship between CI and innovative performance and CI also leads to the creation of innovativeness in small businesses (Hussein, Farzaneh, \& Amiri, 2011; Tanev \& Bailetti, 2008). Hence, to compete effectively, SME must practice CI in their day-to-day business activities. However, far too little researches have centred on the entrepreneur's attitude orientation, CI and innovative performance. Given the fact that CI is important to the SMEs innovativeness, this paper argues that it is essential to understand the entrepreneurial attitude orientation relationships to $\mathrm{CI}$ and innovative performance in their day-to-day business 
practices. Therefore, the purpose of this paper is to investigate the relationships of entrepreneurial attitude orientation, competitive intelligence and innovative performance among the Malaysian SMEs with empirical evidence.

\section{Literature Review and Research Hypotheses}

\subsection{Entrepreneurial Attitude Orientation}

Attitude is an evaluation of an object of thought. Attitude objects can comprise of anything a person may hold in mind, ranging from the mundane to the abstract, including things, people, groups, and ideas (Bohner \& Dickel, 2011). Attitude exists at the general level and also at a very specific level for many objects and because of this, attitude needs to be matched by measurement specificity (Ajzen, 1988; Ajzen \& Madden, 1986). Robinson, Stimpson, Huffner, and Hunt (1991) summarise that attitude towards achievement in general (general object) is not the same as attitude towards achievement in an entrepreneurial setting (specific object). Thus, the Entrepreneurial Attitude Orientation (EAO) incorporates an attitude scale to predict entrepreneurial activity (Robinson et al., 1991). Furthermore, EAO is more domain-specific and increases the correlation with the actual behaviour and reduces unexplained variability (Gibson, Walker, \& Harris, 2010).

The EAO model is based on four theories which are needs for achievement (McClelland, 1961), innovativeness (Kirton, 1984), locus of control (Levenson, 1973), and self esteem (Crandall, 1973). In EAO, the interpretation of achievement, innovativeness, personal control and self esteem can be interpreted as the business accomplishment and undertakings, creativity in handling a business, self-influence over the business destiny and the self-confidence in running a business. However, studies have shown that only three dimensions are commonly identified with business motivation. These dimensions are needs for achievement(NfA), locus of control (LoC) and innovativeness (Qiu,2008; Krauss et al., 2005; Ramsey \& Ibbotson, 2005). In this study, only three dimensions of the EAO are applied. Fishbein and Ajzen (1977) suggest that the attitudinal factor signals a person's judgmental attitude towards a behaviour and a normative belief signal a person's perceived social pressures to act or not to act on a specific behaviour. Thus, EAO constructs such as NfA, LoC and innovativeness may envisage entrepreneur behaviour towards CI.

\subsection{Innovative Performance}

Innovation is defined as the adoption of an idea or behaviour that is new to an organisation (Daft, 1978; Damanpour \& Evan, 1984). The adoption of innovation is described as a process that includes generation, development and implementation of new ideas or behaviours. Innovation is not only an adoption but also an adaptation of new information and practices which lead to the ability to create new ideas and apply them to improvise new products, services, processes and procedures (Bates \& Khasawneh, 2005). The definition of innovation has evolved into different categories which include products, production methods and technologies, markets, services and organisational structure and an assumption is made that the source of information varies between different types of innovation (Freel \& de Jong, 2009; Tödtling, Lehner, \& Kaufmann, 2009). Innovation can either be radical which is revolutionary and original (Green, Gavin, \& Aiman-Smith, 1995) or incremental which are small improvements on an established process, products or services. Innovation is practiced by all types of organisations regardless of size because it is proven that organisations that are innovative has higher profits and market share (Prajogo \& Ahmed, 2006). For the purpose of 
this study, innovative performance is defined as incremental product, service and process innovation because SME's innovation activities are more likely to be ad hoc or project driven (Hoffman, Parejo, Bessant, \& Perren, 1998). Furthermore, SMEs are likely to focus on incremental innovation as posit by Oke, Burke, and Myers (2007).

\subsection{Competitive Intelligence}

Intelligence is defined as the collective value-added benefits obtained from the intangible assets such as knowledge from the employees, management, stakeholders, and customers (Liebowitz, 2006). Knowledge and experience go hand in hand in developing intelligence. The difference between information and intelligence is; information is factual and intelligence is information that has been screened, distilled and analysed (Drucker, 1988; Kahaner, 1996). Interestingly, CI is a product and also a process (Priporas et al., 2005). CI process includes the constructs of planning, collection, analysis, communication, and organisational awareness for decision makers in deciding action (Saayman et al., 2008; Strauss \& du Toit, 2010). CI is a product when the intelligence produced assists the decision makers in formulating a strategy and in making a choice. CI is an ongoing process of analysing data and information into intelligence by applying psychological techniques and new technology to develop competitive edge (Fuld, 2010).

\section{3) Research Framework}

Many literature argue that CI is only popular among the larger organisations but there are several empirical evidences that indicate CI is also applied by SMEs to improve their ability to assess the risk awareness and risk prevention (Zha \& Chen, 2009). Canadian and Iranian small businesses are also involved in CI to increase their innovative performance (Hussein et al., 2011; Tanev \& Bailetti, 2008; Tarraf \& Molz, 2006) and regards CI as crucial to their business success. SMEs in the European Union also have direct support from their governments to support the use of CI by raising awareness campaign and assisting in skill development (Larivet, 2009; Smith, Wright, \& Pickton, 2010). For SMEs to be able to be innovative, Wright, Bisson, and Duffy (2012) advocate SMEs to invest in and practise CI.

Based on the afore-mentioned literature review, the proposed framework (figure1) and the hypotheses are depicted below. EAO constructs are represented by needs for achievement, innovativeness, and locus of control are viewed as possible predictors of competitive intelligence application and innovative performance. Competitive intelligence is also a predictor of innovative performance. CI is also empirically proven to increase innovative performance in SMEs. Given that the role played by the attitudinal factor can signal a person's judgmental attitude towards a behaviour, it then can be anticipated that:

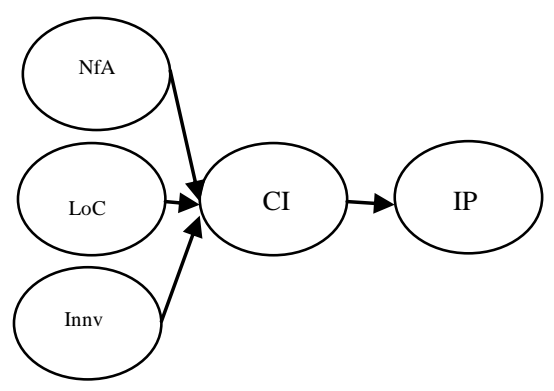

Figure 1: Research Framework 
Hypothesis 1: There will be a positive relationship between NfA and CI.

Hypothesis 2: There will be a positive relationship between LoC and CI.

Hypothesis 3: There will be a positive relationship between innovativeness and CI.

Hypothesis 4: There will be a positive relationship between CI and innovative performance.

\section{4) Methodology}

This study is quantitative in nature and the scope focuses on the SMEs that are registered with the SME Corporation Malaysia either in the manufacturing or services sectors. Since this study focuses on SME entrepreneurs, the definitions of SMEs provided by Small and Medium Industries Development Corporation (SME Corps, 2014) Malaysia will be used to identify appropriate businesses for inclusion in the study. A survey instrument was developed by adapting items from previous literature which are reliable and validated to evaluate the relationships between the EAO constructs and CI and also on innovative performance.

Prior to conducting this study, a pre-testing on the instrument is conducted. Eight entrepreneurs who met the study's prerequisite participated in this pre-testing. The respondents were asked for their feedbacks on the questionnaire face and content validity, content relevance, readability, and to proofread the comprehensiveness, syntax errors and the general format layout. The feedbacks received from these entrepreneurs are compiled and constructively examined before making amendments to the instrument.

Since many SMEs entrepreneurs in Malaysia are comfortable in answering in the Malay language the instrument is also translated into the Malay language. The translation in this study applied the extended parallel translation procedure known as collaborative translation. By applying this technique the equivalence in meaning and the intended sense of statement is captured (Limpanitgul \& Robson, 2009). Again, the translated questionnaire is being pretested by the respondents to ensure the questions are alike between the English and Malay version questionnaire.

Data is collected by means of mail survey where the questionnaires are distributed to 1000 companies in all states of Malaysia. The respondents are business owners cum entrepreneurs of SMEs. This study is a cross-sectional type of inquiry. Two screening questions are used to check the sample for any form of response bias (Podsakoff, MacKenzie, $\&$ Podsakoff, 2012). A total of 191 replies are received. Twenty-four questionnaires are not usable because they are partially completed and do not meet the screening questions criteria. Therefore, only a sample size of $\mathrm{N}=167$ is used for this study resulting in a response rate of 16.7 percent. This response rate is considered satisfactory because it is a common scenario in Malaysia to obtain a standard response rate of between 15-20\% from the SMEs (Othman, Abdul-Ghani, \& Arshad, 2001). Furthermore, a priori power analysis using the G*Power software (Faul, Erdfelder, Lang, \& Buchner, 2007) revealed that an $\mathrm{N}$ of approximately 119 is needed for an effect size of 0.15 .

\section{5) Findings and Discussion}

The model is tested by using the SmartPLS Structural Equation Modeling (SEM) procedure which is developed by Ringle, Wende, and Will (2010). The first step is to test for the convergent validity. Hair et al. (2010), suggested using the factor loadings, composite 
reliability and average variance extracted to measure the convergence validity. Hair, Hult, Ringle, and Sarstedt (2014) state that outer loadings of 0.7 is acceptable because it is considered close enough to 0.708. Nevertheless, Hair et al. (2014) caution social sciences researchers to initially analyse the impact of deleting indicator between 0.40 and 0.70 on AVE and composite reliability. If by deleting the outer loading does not increase measure above the threshold, the reflective indicator should be retained. However, indicators with outer loading below 0.40 should always be eliminated from the scale (Hair, Sarstedt, Pieper, \& Ringle, 2012). The loadings after deleting some of the items exceeded the recommended value of 0.7 (Hair et al. 2010) as depicted in Table I. The Composite Reliability as depicted in Table 1 ranged from 0.880 to 0.959 which exceeded the recommended value of 0.7 (Hair et al., 2010). The average variance extracted, which reflects the overall amount of variance in the indicators accounted for by the latent construct, was in the range of 0.587 and 0.776 which also exceeded the recommended value of 0.5 (Hair et al., 2010).

Table 1

Result of the measurement model

\begin{tabular}{|c|c|c|c|c|c|}
\hline Construct & Item & Loadings & AVE & CR & $\begin{array}{l}\text { Item(s) deleted due to } \\
\text { low loadings }\end{array}$ \\
\hline \multirow[t]{14}{*}{ Competitive Intelligence } & $\mathrm{CI} 2$ & 0.761 & 0.624 & 0.959 & Item CI \\
\hline & $\mathrm{CI} 3$ & 0.745 & & & Item CI5 \\
\hline & CI4 & 0.762 & & & Item CI15 \\
\hline & CI6 & 0.767 & & & \\
\hline & $\mathrm{CI} 7$ & 0.842 & & & \\
\hline & CI8 & 0.842 & & & \\
\hline & CI9 & 0.752 & & & \\
\hline & CI10 & 0.783 & & & \\
\hline & CI11 & 0.850 & & & \\
\hline & CI12 & 0.850 & & & \\
\hline & CI13 & 0.775 & & & \\
\hline & CI14 & 0.842 & & & \\
\hline & CI16 & 0.743 & & & \\
\hline & CI17 & 0.727 & & & \\
\hline \multirow[t]{6}{*}{ Innovative performance } & IP1 & 0.800 & 0.587 & 0.895 & \\
\hline & IP2 & 0.799 & & & \\
\hline & IP3 & 0.792 & & & \\
\hline & IP4 & 0.653 & & & \\
\hline & IP5 & 0.766 & & & \\
\hline & IP6 & 0.788 & & & \\
\hline \multirow[t]{12}{*}{ EAO } & NFA1 & 0.891 & 0.776 & 0.933 & \\
\hline & NFA2 & 0.875 & & & \\
\hline & NFA3 & 0.878 & & & \\
\hline & NFA4 & 0.880 & & & \\
\hline & LOC5 & 0.859 & 0.710 & 0.880 & Item LOC7 \\
\hline & LOC6 & 0.799 & & & Item LOC9 \\
\hline & LOC8 & 0.868 & & & Item LOC10 \\
\hline & Innv11 & 0.793 & 0.618 & 0.889 & \\
\hline & Innv12 & 0.720 & & & \\
\hline & Innv13 & 0.848 & & & \\
\hline & Innv14 & 0.844 & & & \\
\hline & Innv15 & 0.715 & & & \\
\hline
\end{tabular}

Note: Loadings $>0.7, \mathrm{AVE}>0.5, \mathrm{CR}>0.7$

The next step is to measure the discriminant validity to check if the construct is exclusive from the other constructs by empirical standard (Hair et al., 2014). As shown in Table 2, the correlations for each construct is less than the square root of the average variance 
extracted by the indicators measuring that construct, indicating adequate discriminant validity. In total, the measurement model demonstrates adequate convergent validity and discriminant validity.

Table 2

Discriminant Validity of Construct

\begin{tabular}{cccccc}
\hline & CI & INNV & IP & LOC & NFA \\
\hline CI & $\mathbf{0 . 7 9 0}$ & & & & \\
INNV & 0.486 & $\mathbf{0 . 7 8 6}$ & & & \\
IP & 0.651 & 0.462 & $\mathbf{0 . 7 6 6}$ & & \\
LOC & 0.426 & 0.705 & 0.452 & $\mathbf{0 . 8 4 2}$ & \\
NFA & 0.346 & 0.429 & 0.300 & 0.671 & $\mathbf{0 . 8 8 1}$ \\
\hline
\end{tabular}

Note: Diagonals represent the square root of the AVE while the off diagonals represent the correlations.

To test the hypotheses, an evaluation on the structural model is conducted. The analysis for the hypotheses is performed using the bootstrapping method. This method takes a large number of cases from the original sample with replacement (Hair, Black, Babin, \& Anderson, 2010). Bootstrapping procedure is to test the coefficients for their significance. Table 3 shows that $\mathrm{H} 1, \mathrm{H} 3$ and $\mathrm{H} 4$ are supported. NfA and innovation are positively related to competitive intelligence. CI is positively related to innovative performance. From Figure 1, the innovative performance $\mathrm{R}^{2}$ value is 0.423 which suggests that $42.3 \%$ of the variance in the dependent variable is explained by CI. The CI $\mathrm{R}^{2}$ value is 0.260 which suggests $26.0 \%$ of the variance in the $\mathrm{CI}$ is explained by the EAO constructs which are NfA, LoC and innovativeness.

Table 3

Hypothesis testing

\begin{tabular}{llccc}
\hline Hypotheses & Relationship & BETA & Std Error & T Value \\
\hline H1 & NFA -> CI & 0.139 & 0.087 & $1.607^{*}$ \\
H2 & LOC -> CI & 0.063 & 0.102 & 0.618 \\
H3 & INNV -> CI & 0.381 & 0.078 & $4.683^{* * *}$ \\
H4 & CI -> IP & 0.650 & 0.041 & $16.050^{* * *}$ \\
\hline
\end{tabular}

Note: $* \mathrm{p}<0.10(1.28),{ }^{* *} \mathrm{p}<0.05(1.645),{ }^{* * *} \mathrm{p}<0.01(2.33)$ one tail. Hypotheses are supported.

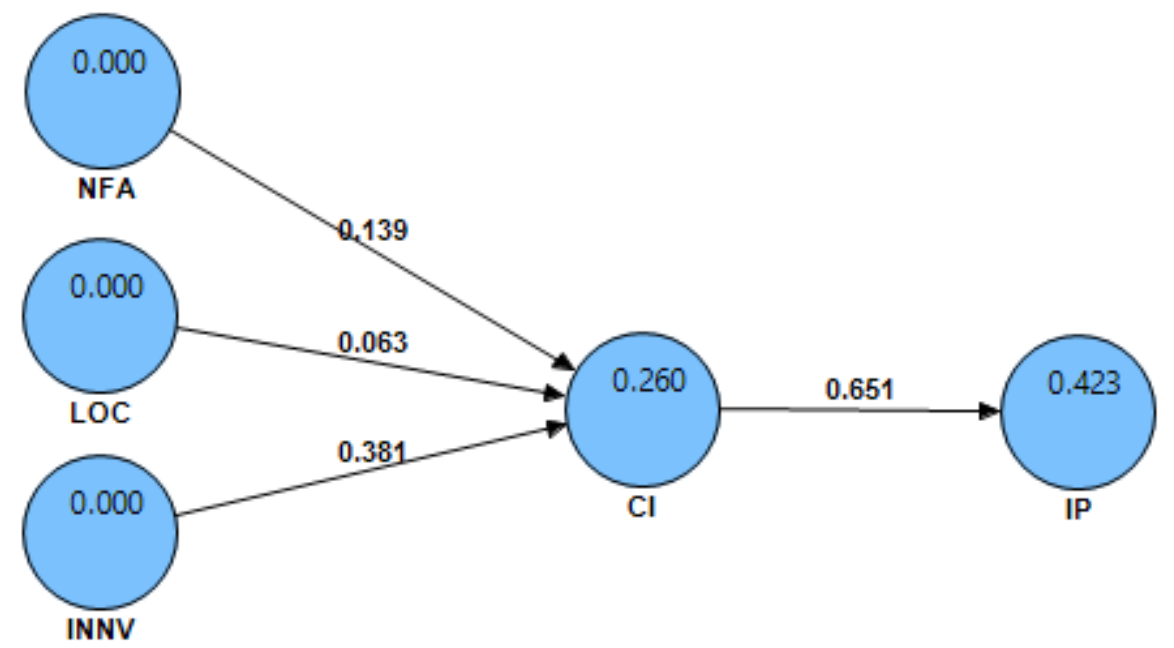

Figure 2. Structural Model 
NfA is positively related to innovative performance with a beta value of 0.139 , $t$-value of 1.607 and $\rho<0.10$ significance level. Many scholars have argued that NfA has a positive correlation with the psychological needs. Due to their desire to succeed, entrepreneurs are able to predict new initiative that will contribute to the development of their venture success. (Phelan \& Alder, 2005; Spence, Gherib, \& Biwolé, 2011). Critically, McClelland (1961) work also emphasises that entrepreneurs with high NfA will find ways to maximise their economic achievement. This view implies that entrepreneurs NfA are more critical than the economic conditions supporting their potential innovations (de Beer, Sowa, \& Holman, 2014). Therefore, there is some evidence that an entrepreneur with high NfA also has a tendency to embrace CI to create innovation to maximise his economic achievement.

Innovativeness is also positively related to $\mathrm{CI}$ with a beta value of $0.381, \mathrm{t}$-value of 4.683 and $\rho<0.01$ significance level. Innovativeness is defined as a person's willingness to venture into a new product or service (Goldsmith \& Hofacker, 1991). Given that innovation has financial, imitation (Escribano \& Giarratana, 2011) and success risks (Cormican \& O'Sullivan, 2004) entrepreneurs are more robust in accessing about the innovation potential (Dereli \& Altun, 2013). Thus, the result suggests a strong link exists between innovativeness and CI as it may lead to innovation intelligence.

Rotter (1966) made a significant contribution to the psychological field with the development of locus of control construct. According to him an individual perceives the outcome of an event as being either within or beyond his or her personal control and understanding. An internal LoC is one that believes he has influence over the outcomes through his ability, effort or skills. On the other hand, external LoC means those forces from outside control the individual and determine the outcomes. Scholars have argued that internal LoC orientation is a prerequisite for entrepreneurs to take action (Krueger, 1993; Mueller \& Thomas, 2001). Contrary to expectation, this study result shows that the relationship between LoC and CI is not statistically significant. This rather contradictory result may be due to cultural differences. Malaysia shows a strong endorsement of being a high power distance and a collectivistic society (Arrindell et al., 1997; Hofstede, 1983; Kühnen et al., 2001) where decisions are made by members of a group rather than individuals. Thus this result is no surprise because it is expected that an internal LoC orientation would be less prevalent in collectivistic cultures than in individualistic cultures.

$\mathrm{CI}$ is positively related to innovative performance with a beta value of $0.650, \mathrm{t}$-value of 16.050 and $\rho<0.01$ significance level. This result corroborates the findings by Hussein et al. (2011) and Tanev and Bailetti (2008) that CI leads to innovativeness, creation of ideas and increase in innovative performance among the SMEs. This also leads to a strong support to the reasoning by Petrişor and Străin (2013), Jaworski, Macinnis, and Kohli (2002) and Krücken-Pereira, Debiasi, and Abreu (2001) that CI is a tool for innovation that supports an organisation's business strategy, market penetration, and development and product innovation. Therefore, competitive intelligence is a tool that assists in the development of an innovative performance of an organisation.

\section{6) Conclusion and Implication}

The objective of this study is to examine the EAO constructs, CI and innovative performance relationship in the Malaysian SMEs context. This study makes several contributions to the literature on strategic management. Firstly, this study extends the pool of literature by examining the EAO, CI and innovative performance. Secondly, it is vital for the 
Multinational companies (MNC) to understand the SMEs attitude orientation of an Asian emerging country because of its unique historical background, religious beliefs and practices, philosophical influences, political systems and cultures. MNC in Malaysia is known to outsourcing many non-core businesses to SMEs. From this study, the result is in agreement with Hofstede's cultural dimensions theory that the effects of a society's culture on the values of its members plays an important role in influencing the entrepreneur behaviour. It seems clear that this study acknowledges that EAO and CI are positively related to innovative performance but only NfA and innovativeness exhibit significant relationship with competitive intelligence. Finally, competitive intelligence is also confirmed as a tool to boost innovative performance.

The findings from this study clearly show that CI is indeed important for Malaysian SME economic success. The success of the Malaysian SMEs is very much affected by the entrepreneurs' attitude in engaging new techniques to accelerate innovative performance. From this study, there is a consensus that the entrepreneur attitude is the decisive factor in engaging CI. This study's empirical evidence also indicates that CI boosts innovative performance. Thus, entrepreneurs must have the right mindset when undertaking innovative development and competitive intelligence is able to accelerate this concern. SMEs are advised to embrace a new way of increasing innovative performance or they are at risk of being left behind in today's borderless market place. They must make use of formal techniques in gathering intelligence about their surroundings. Nevertheless, it is important for the SMEs to have a mindset that recognises the fact that innovativeness can be achieved by adopting new techniques and changing the deep-rooted system. The study also confirms that EAO is an antecedent of $\mathrm{CI}$; and it may be useful not only to the entrepreneurs but also for employees in the private and public sectors to inculcate the EAO to achieve a culture of innovative performance. Government agencies can initiate awareness campaign to promote $\mathrm{CI}$ among the SMEs. They can also identify SMEs that show potential growth and offer CI programmes at both the start up and growth stages. In addition, collaborations can also be established between the universities and the SMEs through partnerships to encourage the use of CI.

\section{REFERENCES}

Adidam, Phani Tej, Banerjee, Madhumita, \& Shukla, Paurav. (2012). Competitive intelligence and firm's performance in emerging markets: An exploratory study in India. Journal of Business \& Industrial Marketing, 27(3), 242-254. doi: 10.1108/08858621211207252

Ajzen, I. (1988). Attitudes, personality and behaviour. Chicago, IL: The Dorsey Press.

Ajzen, I., \& Madden, T.J. (1986). Perdiction of goal-directed behavior: Attitudes, intentions and perceived behavioral control. Journal of Experimental Social Psychology, 22, 453-474.

Arrindell, W. A, Hatzichristou, C., Wensink, J., Rosenberg, E., van Twillert, B., Stedema, J., \& Meijer, D. . (1997). Dimensions of national culture as predictors of cross-national differences in subjective well-being. Personality and Individual Differences, 23(1), 37-53.

Bates, R., \& Khasawneh, S. (2005). Organizational learning culture, learning transfer climate and perceived innovation in Jordanian organizations. International Journal of Training and Development, 9, 96-109.

Bohner, G., \& Dickel, N. (2011). Attitudes and attitude change. Annual Review of Psychology, 62, 391-417. 
Cormican, K., \& O’Sullivan, D. . (2004). Auditing best practice for effective product innovation management. Technovation, 24(10), 819-829.

Crandall, R. (1973). Measurement of self-esteem and related constructs. In J. P. Robinson \& P. R. Shaver (Eds.), Measurement of social psychological atititudes. Ann Arbor: University of Michigan.

Daft, Richard. L. (1978). A dual-core model of organizational innovation. Academy of Management Journal, 21(2), 193-210. doi: 10.2307/255754

Damanpour, Fariborz, \& Evan, Wiliam M. (1984). Organizational innovation and performance: The problem of "organizational lag". Administrative Science Quarterly, 29(3), 392-409.

de Beer, Jeremy, Sowa, Izabella, \& Holman, Kristen. (2014). Frameworks for Analysing African Innovation: Entrepreneurship, the Informal Economy and Intellectual Property. Innovation \& Intellectual Property, 32.

Dereli, TüRkay, \& Altun, Koray. (2013). A novel approach for assessment of candidate technologies with respect to their innovation potentials: Quick innovation intelligence process. Expert Systems with Applications, 40(3), 881-891.

Drucker, P.F. (1988). The coming of the new organization Harvard Business Review on Knowledge Management: Harvard Business School Press.

Escribano, A., \& Giarratana, M. S. . (2011). EU patent system: To be or not to be? Economic Series Working paper, 01-11.

Faul, F., Erdfelder, E., Lang, A-G., \& Buchner, A. (2007). G* Power 3: A flexible statistical power analysis program for the social, behavioral, and biomedical sciences. Behavior research methods, 39(2), 175-191.

Fishbein, \& Ajzen. (1977). Attitude-behavior relations: A theoretical analysis and review of empirical research. Psychological Bulletin, 84, 888-918.

Freel, M., \& de Jong, J.P.J. . (2009). Market novelty, competence-seeking and innovation networking Technovation, 29(12), 873-884.

Fuld, Leonard M. (2010). The secret language of competitive intelligence: How to see through and stay ahead of business distruptions distortions, rumors and smoke screens. Indianapolis, IN: Dog Ear Publishing.

Gibson, S.G., Walker, P., \& Harris, M. (2010). Investigating the entrepreneurial attitudes of African Americans: A study of young adults. Small Business Institute ${ }^{\circledR}$ National Conference Proceedings, Vol. 34(1 (Winter)), 101-111.

Goldsmith, RE., \& Hofacker, CF. (1991). Measuring consumer innovativeness. Journal of the Academy of Marketing Science, 19(3), 201-221.

Green, S., Gavin, M., \& Aiman-Smith, L. . (1995). Assessing a multidimensional measure of radical technological innovation. IEEE Transactions on Engineering Management, 42(3), 203-214.

Hair, J.F., Black, W.C., Babin, B.J., \& Anderson, R.E. (2010). Multivariate data analysis. Upper saddle River, NJ: Pearson Education, Inc.

Hair, J.F., Hult, G. Tomas M., Ringle, C.M., \& Sarstedt, Marko. (2014). A primer on partil least squares structural equation modeling (PLS-SEM). Los Angeles, USA: SAGEPublications, Inc.

Hair, J.F., Sarstedt, M, Pieper, T, \& Ringle, C.M. (2012). The use of partial least squares structural equation modeling in strategic management research: A review of past practices and recommendations for future applications. Long Range Planning, 45, 320-340.

Hoffman, Kurt, Parejo, Milady, Bessant, John, \& Perren, Lew. (1998). Small firms, R\&D, technology and innovation in the UK: A literature review. Technovation, 18(1), 39-55. doi: http://dx.doi.org/10.1016/S0166-4972(97)00102-8 
Hofstede, G. (1983). Dimensions of national cultures in fifty countries and three regions. In J. Deregowski, S. Dzuirawiec \& R. Annis (Eds.), Explications in cross-cultural psychology. Lisse, Switzerland: Swets and Zeitlinger.

Hussein, Rezaie Dollatabady, Farzaneh, Ghandehari, \& Amiri, Farham. (2011). Analyzing the impact of competitive intelligence on innovation at scientific research centers In Isfahan science and technology town. Interdisciplinary Journal of Contemporary Research in Business, 3(5), 940-948.

Jaworski, Bernard J., Macinnis, Deborah J., \& Kohli, Ajay K. (2002). Generating competitive intelligence in organizations. Journal of Market-Focused Management, 5(4), 279-307. doi: 10.1023/b:jmfm.0000008071.19917.36

Kahaner, L. (1996). Competitive intelligence. New York: Simon and Schuster.

Kirton, Michael J. (1984). Adaptors and innovators-Why new initiatives get blocked. Long Range Planning, 17(2), 137-143.

Krauss, S.I., Frese, M., Friedrich, C., \& Unger, J.M. . (2005). Entrepreneurial orientation: A psychological model of success among southern African small business owners. European Journal of Work \& Organizational Psychology, 14(3), 315-344.

Krücken-Pereira, L., Debiasi, F., \& Abreu, A. F. (2001). Technological innovation and competitive intelligence: An interactive process. READ - Electronic Journal of Directors, 7.

Krueger, N. . (1993). The impact of prior entrepreneurial exposure on perceptions of new venture feasibility and desirability. Entrepreneurship Theory and Practice 18(1), 3-21.

Kühnen, U, Hannover, B, Roeder, U, Shah, Ashiq Ali, Schubert, B, Upmeyer, A, \& Zakaria, Saliza. (2001). Cross-cultural variations in identifying embedded figures comparisons from the United States, Germany, Russia, and Malaysia. Journal of Cross-Cultural Psychology, 32(3), 366-372.

Larivet, S. (2009). Economic intelligence in small and medium business in France: A survey Paper presented at the 3rd European Competitve Intelligence Symposium, Mälardalen University Stockholm, Sweden.

Levenson, H. (1973). Multidimensional locus of control in psychiatric patients. Journal of Counseling and Clinical Psychology, 41, 397-404.

Liebowitz, Jay. . (2006). Strategic intelligence: Business intelligence, competitive intelligence, and knowledge management. Boca Raton, FL: Auerbach Publications.

Limpanitgul, T, \& Robson, M. (2009). Methodological considerations in a quantitative study examining the relationship between job attitudes and citizenship behaviors. Paper presented at the 18th EDAMBA Summer Academy, Soreze, France.

McClelland, D.C (1961). The achieving society. New York, NY and London: CollierMacmillan.

Mueller, S L, \& Thomas, A S. (2001). Culture and entrepreneurial potential: A nine country study of locus of control and innovativeness. Journal of business venturing, 16(1), 5175.

Oke, A., Burke, G., \& Myers, A. . (2007). Innovation types and performance in growing UK SMEs. International Journal of Operations \& Production Management, 27(7), 735753.

Othman, R., Abdul-Ghani, R., \& Arshad, R. (2001). Great expectations. CEOs'perception of the performance gap of the HRM function in the Malaysian manufacturing sector. Personnel Review, 30(1), 61-80.

PEMANDU. (2010). Economic transformation programme. A roadmap for Malaysia. Putrajaya, MY: Performance Management and Delivery Unit,Prime Minister's Department. 
Petrişor, I., \& Străin, NA. (2013). Approaches on the competitive intelligence. USV Annals of Economics \& Public Administration, 13(1), 100-109.

Phelan, SE, \& Alder, S. (2005). An experimental study of entrepreneurial exploitation. Paper presented at the The annual meeting of the Academy of Management, Honolulu, HI.

Podsakoff, P.M., MacKenzie, S.B., \& Podsakoff, N.P. (2012). Sources of method bias in social science research and recommendations on how to control it. Annual Review of Psychology, 63(1), 539-569. doi: doi:10.1146/annurev-psych-120710-100452

Prajogo, D. I., \& Ahmed, P. K. . (2006). Relationship between innovation stimulus, innovation capacity, and innovation performance. $R \& D$ Management 36(5), 499-515. doi: http://dx.doi.org/10.1111/j.1467-9310.2006.00450.x

Priporas, C.V., Gastoris, L. , \& Zacharis, V. (2005). Competitive intelligence activity: Evidence from Greece. Marketing Intelligence \& Planning, 23(7), 659-669.

Ramsey, E., \& Ibbotson, P. . (2005). Entrepreneurial SMEs: An Irish study of micro and macro influences. Journal of International Entrepreneurship, 3(4), 317-332.

Ringle, Christian M, Wende, Sven, \& Will, Alexander. (2010). Finite mixture partial least squares analysis: Methodology and numerical examples. In V. E. Vinzi, W. W. Chin, J. Henseler \& H. Wang (Eds.), Handbook of Partial Least Squares (pp. 195-218). Berlin, Heidelberg: Springer.

Robinson, P.B., Stimpson, D.V., Huffner, J.C., \& Hunt, H.K. (1991). An attitude approach to the prediction of entrepreneurship. Entrepreneurship Theory \& Practice, 15(4), 13-31.

Rotter, J.B. (1966). Generalized expectancies for internal versus external control of reinforcement. Psychological Monographs: General and Applied, 80 (Serial No. 609).

Saayman , Andrea, Pienaar, Jaco, Pelsmacker, Patrick de, Viviers, Wilma, Cuyvers, Ludo, Muller, Marie-Luce, \& Jegers, Marc. (2008). Competitive intelligence: construct exploration, validation and equivalence. Aslib Proceedings, 60(4), 383-411.

Smith, Jamie R., Wright, Sheila, \& Pickton, David. (2010). Competitive intelligence programmes for SMEs in France: Evidence of changing attitudes. Journal of Strategic Marketing, 18(7), 523-536. doi: 10.1080/0965254x.2010.529154

Spence, M, Gherib, JBB, \& Biwolé, VO. (2011). Sustainable entrepreneurship: is entrepreneurial will enough? A north-south comparison. Journal of business ethics, 99(3), 335-367.

Star Business. (2013). Govt targets SMEs contributing 40\% to GDP by 2015. The Staronline [Business news]. Kuala Lumpur, MY: Star Publications (M) Bhd

Strauss, A. C., \& du Toit, A. S. A. (2010). Competitive intelligence skills needed to enhance South Africa's competitiveness. Aslib Proceedings, 62(3), 302-320. doi: $10.1108 / 00012531011046925$

Tanev, Stoyan, \& Bailetti, Tony. (2008). Competitive intelligence information and innovation in small Canadian firms. European Journal of Marketing, 42(7-8), 786-803. doi: 10.1108/03090560810877150

Tarraf, Patrick, \& Molz, Rick. (2006). Competitive intelligence at small enterprises. SAM Advanced Management Journal (07497075), 71(4), 24-34.

Tödtling, Franz, Lehner, Patrick, \& Kaufmann, Alexander. (2009). Do different types of innovation rely on specific kinds of knowledge interactions? Technovation, 29(1), 5971. doi: 10.1016/j.technovation.2008.05.002

Wright, S., Bisson, Christophe, \& Duffy, Alistair P. (2012). Applying a behavioural and operational diagnostic typology of competitive intelligence practice: Empirical evidence from the SME sector in Turkey. Journal of Strategic Marketing, 20(1), 1933. doi: $10.1080 / 0965254 x .2011 .628450$

Wright, S., Pickton, D.W., \& Callow, J. (2002). Competitive intelligence in UK firms: a typology. Marketing Intelligence \& Planning, 20(6), 349-360. 
Zha, Xianjin, \& Chen, Minghong. (2009). Competitive intelligence monitoring in the risk prevention of SMEs. Journal of Service Science and Management, 3, 230-235. doi: 10.4236/jssm.2009.23028 